\title{
Determination of Chlorogenic Acid Levels In Selected Kenyan Tea Cultivars by HPLC-PDA
}

\author{
Gladys N Onsando ${ }^{1 *}$, John K Wanyoko ${ }^{2}$ and Simon M King'ori ${ }^{2}$ \\ ${ }^{1}$ Kenya Agricultural and Livestock Research Organization (KALRO)-Tea Research Institute, Chemistry Department, Kericho, Kenya \\ ${ }^{2}$ Chemistry Department, Kericho, Kenya
}

Received: March 02, 2016; Accepted: May 20, 2016; Published: June 10, 2016

*Corresponding author: Gladys N Onsando, Kenya Agricultural and Livestock Research Organization (KALRO)-Tea Research Institute, Chemistry Department, Kericho, Kenya.P. O. Box 820 20200; Tel:0723565972; Email: gladys.onsando@yahoo.com

\begin{abstract}
Tea, a beverage that is consumed worldwide, contains several bioactive compounds. They include Chlorogenic Acid (CGA) which has been reported to be of health benefits. In this study, CGA levels were assessed in 17 Kenyan tea cultivars. Two leaves and a bud were sampled by hand plucking from a clonal trial set in Timbilil estate, Kericho County. A Chinese herb, Moringa oleifera, was included for comparison purposes as it is known to have high levels of CGA. The leaves of the Moringa oleifera tree have been reported to demonstrate antioxidant activity due to its high amount of polyphenols. A wide variety of nutritional and medicinal virtues have been attributed to it partly due to amounts of CGA in it. This is an indication that some of the Kenyan tea cultivars used in this study would have health benefits equivalent to those attributed to Moringa oleifera. The screening was done using a High Performance Liquid Chromatography (Shimadzu, Japan) equipped with a photo-diode array detector (SPD-M20A). The Chlorogenic acid levels ranged between $4.2 \mathrm{mg} / \mathrm{g}-22.0 \mathrm{mg} / \mathrm{g}$ in the selected Kenyan tea cultivars, while Moringa oleifera had about 25.0 $\mathrm{mg} / \mathrm{g}$.
\end{abstract}

\section{Introduction}

Tea, derived from the leaves of Camellia sinensis, is the world's second most popular beverage after water [6]. Its leaves are, apart from wine, fruit and vegetables, a very good source of polyphenolic compounds [16]. Teais a complex matrix and contains a number of bioactive molecules responsible for its health promoting properties. The bioactive molecules include flavonoids, amino acids, caffeine and polysaccharides among others [28, 21]. Quality of tea is related to its contents of alkaloids (caffeine), flavonoids (catechins), phenolic acids (gallic acid, coumeric acid, caffeic acid and chlorogenic acid) and volatile oils (essences) [4].

Phenolic acids and their derivatives are widely distributed in plants, many being essential metabolites. Chlorogenic Acid (CGA) is one of the most widely distributed phenolic derivatives, an important biosynthetic product and natural antioxidant which neutralize free radicals in the body $[25,9]$. The acid is a combination of two molecules comprising a caffeic acid molecule bound to a quinic acid moiety [18].

All CGA isomers are potent antioxidants, as they possess one to two aromatic rings linked to hydroxyl groups and the oneelectron oxidation product of CGAs formed by the reaction with free radicals is rapidly broken down to non-free radical products [27]

The phenolic compound has antibacterial, antifungal, antioxidant and antitumor activities [26, 17]. The fungal activity of chlorogenic acid has been demonstrated by its presence on the surface of peaches and inhibition of the cutin-digesting enzyme of the brown rot fungus, Monilinia fruticola [15]. The anti-oxidant properties of CGA and its isomers are suggested to play an important role in protecting food, and living cells and organs from oxidative degeneration [8, 3, 23]. Diets rich in CGAs play a great role in preventing various diseases associated with oxidative stress such as cancer, cardiovascular, aging, and neurodegenerative disease $[22,13]$.

A series of experiments carried out by G. Frankline et al show that chlorogenic acid has a potential role in shoot, root and root hair development. They revealed that an optimum CGA level is necessary for their proper development. Other studies by S. Lavee et al have shown that fruiting shoots the induction period with a high level of CGA and non-fruiting with a low one.

Among the main climatic variables that influence the growth of the tea plant is the soil water deficit. Water stress results in an accumulation of phenolic compounds after a period of 4-8 days followed by a decline of them under prolonged water stress, [7].

The Moringa plant is well known and almost all parts are used culturally for its nutritional and therapeutic values, purported medicinal properties and for taste and flavor as a vegetable and seed $[1,2]$, this is attributed to amounts of CGA in it [11, 21, 20, 23 and 9]. Investigations of $M$. oleifera leaves have reported antiinflammation, anti-infection, anti-diabetic, antioxidant, and antihyper lipidemic activities [5].

Previous works on chlorogenic acid have been on a number 
Table 1: Showing the Genetic Characteristics of Cultivars [11].

\begin{tabular}{|c|c|c|}
\hline Clone & Varietal Type & $\begin{array}{c}\text { Source Of Material } \\
\text { (Stock/Pedigree) }\end{array}$ \\
\hline TRFK 303/577 & Assam/ China hybrid & OP progeny of TRFK $6 / 8$ \\
\hline TRFK 12/19 & Assam & Field selection \\
\hline TRFK 6/8 & Assam/Chinary hybrid & Field selection \\
\hline TRFK $100 / 5$ & Assam & Field selection \\
\hline TRFK $12 / 12$ & Assam / Chinary hybrid & Field selection \\
\hline TRFK 31/11 & Assam & Field selection \\
\hline TRFK 31/8 & Assam & Field selection \\
\hline TRFK $11 / 4$ & Assam/Chinary hybrid & Field selection \\
\hline TRFK 7/3 & Assam & Field selection \\
\hline TRFK $7 / 9$ & Assam/Chinary hybrid & Field selection \\
\hline TRFK 54/40 & Assam & Field selection \\
\hline TRFK 56/89 & Chinary & Field selection \\
\hline TRFK 108/82 & Assam & Field selection \\
\hline TRFK 303/216 & Assam & $\begin{array}{c}\text { Open pollinated progeny } \\
\text { of TRFK } 6 / 8\end{array}$ \\
\hline TRFK 303/259 & Assam & $\begin{array}{c}\text { Open pollinated progeny } \\
\text { of TRFK } 6 / 8\end{array}$ \\
\hline TRFK $11 / 52$ & Assam & Field selection \\
\hline TRFK $11 / 26$ & Assam & Field selection \\
\hline
\end{tabular}

of plants, for example coffee, and plant extracts, for example Lonicerajaponica Thunb, Flos Lonicerae and Eucommia ulmoides Oliver. But none has been carried out on the tea plant. Therefore, the objective of this pioneer study was to determine the variation in levels of chlorogenic acid in selected Kenyan tea cultivars. Due to the growing interest in the biological, physiological and antioxidant properties of chlorogenic acid, it is imperative that the levels in the tea plant be quantified. Chlorogenic acid has been shown to be an antioxidant and its concentrations have not been determined in the Kenyan tea clones, hence the need to quantify.

\section{Materials and Methods}

\section{Experimental design and sampling procedure}

The study was carried out in Timbilil estate $\left(0^{\circ} 22^{\prime} \mathrm{S}, 35^{\circ} 21^{\prime} \mathrm{E}\right.$ and an altitude of 2180 meters (mean above sea level), Kenya Agricultural and Livestock Research Organization - Tea Research Institute (KALRO-TRI). The experiment was superimposed on an existing trial involving twenty clones maintained uniformly under recommended agronomic practices as outlined in the Tea Grower's Hand Book (TRFK, 2002). The trial was laid out in a randomized complete block design comprising twenty plots of sixty plants each replicated three times. The 17 cultivars used in this study were; TRFK $11 / 26$, TRFK $6 / 8$, TRFK $7 / 9$, TRFK 12/12, TRFK 12/19, TRFK 11/52, TRFK 31/8, TRFK 7/3, TRFK 31/11, TRFK 11/4, TRFK 100/5, TRFK 56/89, TRFK 303/259, TRFK 303/577, TRFK 54/40, TRFK108/82 and TRFK 303/216. Moringa oleifera, a known Chinese herb, was used for comparison purposes.

Sampling was done according to the method described by Owuor and Obanda [24]. Two leaves and a bud were hand plucked and immediately steamed (PHILIPS) for one minute before being dried in an oven (UNITEMP) at $80^{\circ} \mathrm{C}$ for 24 hours. The dried samples were ground to a fine powder using an electric coffee miller (AR 40, Moulinex, China) and stored in aluminumlined paper bags prior to analysis.

\section{Chemicals and reagents}

HPLC grade Ethanol was purchased from Scharlab S. L., Mas d'En Cisa, Spain. HPLC grade Methanol was purchased from Fisher Scientific, UK. HPLC grade acetonitrile and phosphoric acid were purchased from Sigma-Aldrich, St. Louis, MO, USA. The Chlorogenic acid primary reference standard (94.69\%) was purchased from HWI ANALYTIK GMBH, Germany.

\section{Sample preparation}

Sample preparation for HPLC analysis was as described by Jiagen Wen, Liqun Kang and Yuxiang Chen (2012), with modification in the weight of sample. Approximately 5.0gof the powdered sample was weighed and transferred to a conical flask. To this, $45 \mathrm{~mL}$ of aqueous methanol $(50: 50 \mathrm{v} / \mathrm{v})$ was added and stirred (Corning Hot Plate Stirrer, PC-251) at room temperature for 40 minutes. The mixture was filtered and the residue rinsed with $10 \mathrm{~mL}$ of $50 \%$ methanol. The filtrate was then condensed to approximately $25 \mathrm{~mL}$ by a Rotary Evaporator (Rotavapor, $\mathrm{R}-3000$ ) at $50^{\circ} \mathrm{C}$. After cooling, the liquid was transferred into a $50 \mathrm{~mL}$ volumetric flask and diluted with $50 \%$ aqueous methanol to the volume. A10 mLaliquot was filtered through a $0.45 \mu \mathrm{m}$ millipore filter (SATORIUS 2500-047 N), centrifuged at $60 \mathrm{rpm}$ (HSCEN - 204) for 15 minutes and assayed by HPLC.

\section{Sample analysis}

A standard stock solution of CGA was prepared by accurately weighing $25 \mathrm{mg}$ in $1 \mathrm{ml}$ of HPLC grade ethanol. From the stock, six working standards with concentrations of 3.92, 7.84, 23.52, 39.2, 54.88 and $78.4 \mathrm{mg} / \mathrm{L}$ were prepared by serial dilution, by use Hamilton micro litre syringe, into $25 \mathrm{~mL}$ volumetric flasks. The working standards were run in the HPLC and used to develop the calibration curve. The figure below shows the chlorogenic acid calibration curve.

\section{Chlorogenic Acid Calibration Curve}

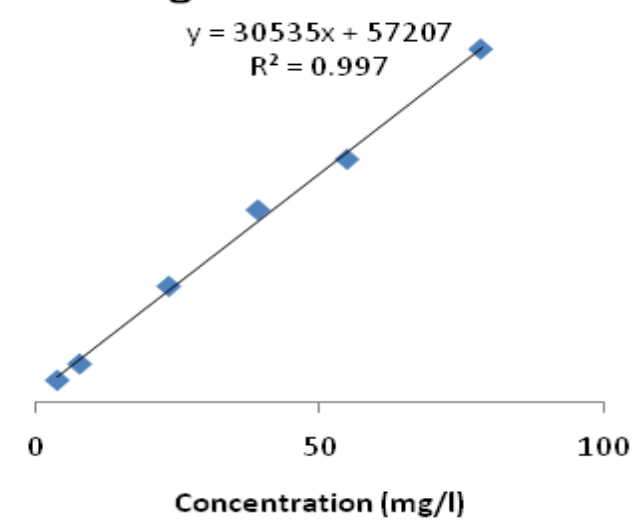


The CGA content was determined and was expressed as milligrams of CGA per gram of the shoot dry weight of respective tea cultivar. The chromatographic system used was equipped with a high precision pump (Shimadzu model LC-10-ATVP, Kyoto, Japan), a PDA detector (Shimadzu SPD-M20A) operating at 327 $\mathrm{nm}$ and a Phenomex Luna $\mathrm{C}_{18}$ column $(250$ x $4.6 \mathrm{~mm}$, i.d $5 \mu \mathrm{m}$ particle size; $100 \AA$ A pore size).A mixture of acetonitrile and $0.5 \%$ phosphoric acid (11.5:88.5 v/v) was used as the mobile phase at a flow rate of $1.0 \mathrm{ml} / \mathrm{min}$. The injection volume was $20 \mu \mathrm{l}$.

\section{Data analysis}

The results obtained were subjected to Analysis Of Variance (ANOVA) using MSTAT statistical software for windows version 2.10 at $\mathrm{p}<0.05$. The Least Significant Difference (LSD) test was used for mean separation where statistically significant differences were observed $(\mathrm{p}<0.05)$.

\section{Results and Discussion}

Results of the CGA levels are presented in Figure 1. M.oleifera had the highest CGA content $(24.64 \mathrm{mg} / \mathrm{g}$ CGA) as compared to the tea varieties. Cultivars TRFK 6/8, 303/216, 12/12, and 54/40 had the highest CGA content at 22.04, 21.83, 18.36 and 17.41 $\mathrm{mg} / \mathrm{g}$, respectively. The lowest CGA levels were recorded in cultivars TRFK 303/259, TRFK 303/577 and TRFK 11/26 which had 4.16, 5.26, $6.02 \mathrm{mg} / \mathrm{g}$, respectively Figure 1. There were significant variations $(\mathrm{p}<0.05)$ in the levels of chlorogenic acid in the cultivars despite the fact that the cultivars were grown in the same geographical location and received same agronomic inputs.

A wide variety of nutritional and medicinal virtues have been attributed to it $[2,10]$ partly due to amounts of CGA in it [11, 21, 20, 23 and 9]. This indicates that Kenyan tea cultivars have the potential to be used as a source of CGA for health benefits as is the case for M.oleifera. From the variability of the CGA levels obtained from this study, it is recommended that more Kenyan tea cultivars should be screened for CGA content and further trial carried on the CGA content in tea. The natural compound of CGA can reliably be determined in tea green leaves by the simple method of HPLC analysis. The quality of tea has been found to depend on the environment and agronomic practices, that is, in terms of soil type, climate and altitude as well as agricultural

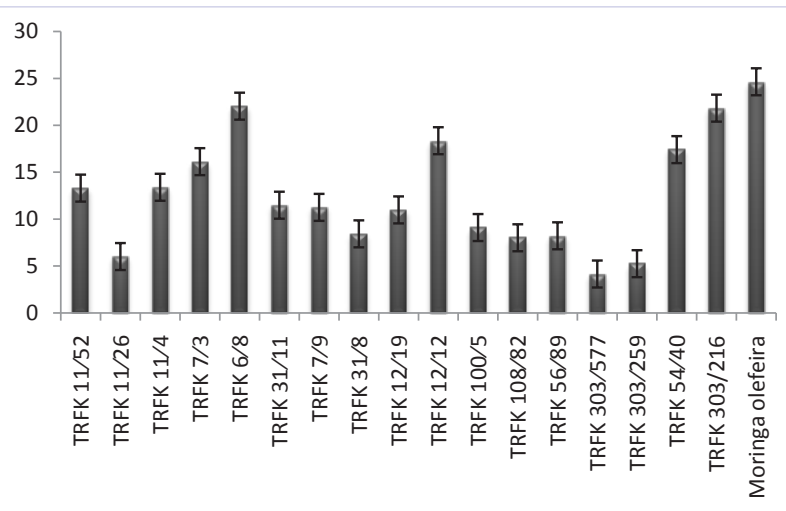

Figure 1: CGA levels in Kenyan tea cultivars and Moringa olefeira. inputs. Studies should, therefore, be carried out to assess the CGA levels under different environments, as some studies indicate environmental factors may have a significant contribution to the content of phenolic acids in plants. Further studies should be undertaken to assess the chlorogenic acid variations in diverse tea environments.

\section{Conclusion}

The natural compound of chlorogenic acid can reliably be determined in green tea leaves by the simple method of HPLC analysis. The observed levels of chlorogenic acid in selected Kenyan clonal teas were found to be significant, presenting the tea clones used in this study as potential sources of CGA. The levels of CGA varied in the different clones used in this study. Different clones may therefore have different levels of health benefits based on their CGA amounts.

\section{References}

1. Anwar F, Latif S, Ashraf M, and Gilani AH. "Moringa olefeira: a food plant with multiple medicinal uses"PhysiotherapyResearch. 2007;21(1):17-25.

2. Arabshahi DS, Devi DV and Urooj, A. Evaluation of antioxidant activity of some plant extracts and their heat, $\mathrm{pH}$ and storage stability. Food Chemistry. 2007;100(3):1100-1105.

3. Belay A and Gholap AV . Characterization and determination of chlorogenic acids (CGA) in coffee beans by UV-Vis spectroscopy. 2009;3(11):234-240.

4. B Alipoor and AH Rad. A Review on the Therapeutical Effects of Tea. Asian Journal of Clinical Nutrition. 2012;4:1-15. DOI:10.3923/ ajcn.2012.1.15

5. BN Singh, BR Singh, RL Singh, Prakash D, Dhakarey R, Upadhyay G, et al. "Oxidative DNA damage protective activity, antioxidant and antiquorum sensing potentials of Moringa oleifera," Food and Chemical Toxicology. 2009;47(6):1109-1116. doi:10.1016/j.fct.2009.01.034.

6. Cabrera C, Artacho R, and Giménez R. Beneficial effects of green tea-a review. Journal of the American College of Nutrition. 2006;25(2):7999.

7. Chakraborty V, Dutta S, and Chakraborty BN. Response of the tea plant to water Stress. Biol. Plant. 2002;45(4):557-562.

8. Cole RA. Phenolic acids associated with the resistance of lettuce cultivars to the lettuce root aphid. Annals of Applied Biology. 1985;106(2):211-217. DOI:10.1111/j.1744-7348.

9. Ncube, Msizi I Mhlongo, Lizelle A Piater, Paul A Steenk, Dubery, Ntakadzeni Madala."Analyses of chlorogenic acids and related cinnamic acid derivatives from Nicotiana tabacum tissues with the aid of UPLC-QTOF-MS/MS based on the in-source collision-induced dissociation method." Chemistry Central Journal. 2014;8(1):66. doi: 10.1186/s13065-014-0066-z

10. Fahey JW. M oleifera: A Review of the Medical Evidence for Its Nutritional, Therapeutic and Prophylactic properties. Part 1. Trees for Life Journal. 2005;1(5).

11. Farah A, Paulis TD, Trugo LC, and Martin PR. Effect of Roasting on the Formation of Chlorogenic Acid Lactones in Coffee. Journal of Agricultural and Food Chemistry. 2005;53:1505-1513.

12. FN Wachira, SM Kamunya, R Chalo, T Maritim and T Kinyangi. TRFK 
Clonal Catalogue, ( $1^{\text {st }}$ edition) Tea Research Foundation of Kenya (TRFK). 2012;151.

13. Fujioka $\mathrm{K}$, and Shibamoto T. Chlorogenic acid and caffeine contentsin various commercial brewed coffees. Food Chemistry. 2008;106(1):217-221. DOI:10.1016/j.foodchem.2007.05.09

14.G Frankline, ACP. Dias in Plant Physiology and Biochemistry. 2011;49(8):835-842.

15. Harbone JB. Do natural plant phenols play a role in ecology? Act Horticulturae. 1994;381(1):36-43.

16. Ho CT, Chen CW, Wanasundara UN, Shahidi F. Natural antioxidant from tea. In: Natura Antioxidants. Chemistry. Health Effects and Applications (ed.F. Shahidi). AOCS Press Champaign, Illinois. 1997; pp.213-223.

17. Jiang Y, Satoh K, Watanabe S, Kusama K and Sakagami H. Inhibition of chlorogenic acid induced cytotoxicity by CoC12. Anticancer Research. 2001;21(5):3349-3353.

18. LA Lallemand, C Zubieta, SG Lee, Y Wang, Acajjaoui S, Timmins J et al . "A structural basis for the biosynthesis of the major chlorogenic acids found in coffee." Plant physiology. 2012;160(1):249-260. doi:10.1104/pp.112.202051

19. Lavee S, Harshemesh H and Aridan N. Phenolic acids - Possible Involvement in Regulating Growth and alternate fruiting in Olive trees. Acta Horticulturae .1986;179(46):317-328. DOI:10.17660/ ActaHortic.

20. Lindsay J, Laurin D, Verreault R, Hebert R, Helliwell B, Hill G.B. et al. Risk factors for Alzheimer's disease: a prospective analysis from the Canadian Study of Health and Aging. American Journal of Epidemiology. 2002;156:445-453.

21. Mak Judith C. "Potential role of green tea catechins in various disease therapies: Progress and promise." Clinical and Experimental Pharmacology and Physiology. 2012;39(3):265-273.doi:10.1111/ j.1440-1681.2012.05673.x

22. Manch C, Scallbert A, Morand C, Remesy C, and Jimenez L. Ployphenols: food sources and bio availability. American Journal of Clinical Nutrition. 2004;79(5):727-747.

23. Moreeira DP, Monteiro MC, Ribeiro-Alves M, Donangelo CM, and Trugo LC. Contribution of chlorogenic acid to the iron reducing activity of coffee beverages. Journal Of Agricultural And Food Chemistry. 2005;53(5):1399-1402.

24. Owuor, P.O. and Obanda, M. The changes in black tea quality due to variations of plucking standard and fermentation time. Food Chemistry. 1998;61(4):435-441.

25. Pietro Gramazio, Jaime Prohe, Mariola Plazas, Isabel Andújar, Francisco Javier Herraiz, Elena Castillo, et al. "Location of chlorogenic acid biosynthesis pathway and polyphenol oxidase genes in a new interspecific anchored linkage map of eggplant." BMC plant biology. 2014;14:350. DOI:10.1186/s12870-014-0350-z.

26. Shao P, Zhang JF, Chen XX, and Sun PL. "Microwave-assisted extraction and purification of chlorogenic acid from by-products of Eucommia Ulmoides Oliver and its potential anti-tumor activity." Journal of Food Science and Technology. 2015;52(8):4925-4934.doi:10.1007/ s13197-014-1571-8.

27. Shibata H, Sakamoto Y, Oka M, and Kono Y. Natural antioxidant, chlorogenic acid, protects against DNA breakage caused by mono chloramine. Bioscience Biotechnology Biochemistry. 1999;63(7):1295-1297.

28. Suzuki, Yasuo, Noriyuki Miyoshi, and Mamoru Isemura. "Healthpromoting effects of green tea." Proceedings of the Japan Academy, Series B. 2012;88(3):88-101. 